\section{Estudo \\ CoDebate}

em Testão

Plamejamento
Revista Estudo \& Debate, Lajeado, v. 25, n. 2, 2018. ISSN 1983-036X

DOI: http://dx.doi.org/10.22410/issn.1983-036X.v25i2a2018.1498

\title{
A LOGÍSTICA REVERSA E A RECICLAGEM DE COMPONENTES ELETRÔNICOS COMO OPÇÓES SUSTENTÁVEIS: ANÁLISE DE UM PROJETO NO ESTADO DE MATO GROSSO ${ }^{1}$
}

\author{
Djeimella Ferreira de Souza ${ }^{2}$, Loanna Rodrigues Silva ${ }^{3}$, Nathália Prochnow Nagai ${ }^{4}$, \\ Paulo Henrique Martins Desidério5
}

\begin{abstract}
Resumo: $\mathrm{O}$ processo de inovação tecnológica em componentes eletrônicos possibilitou acesso irrestrito da sociedade à informação e produtos tecnológicos em seu cotidiano. No entanto, a velocidade da perspectiva schumpteriana de destruição criativa nas substituições destes produtos por melhores promoveu um impacto nas políticas de gestão ambiental, a do lixo eletrônico. Dessa forma, uma discussão sobre os caminhos reversos destes equipamentos pode minimizar efeitos ambientais relevantes. Percebe-se também uma busca da indústria por materiais com menor impacto ambiental, capacidade de reuso e possibilidade de redução de custos produtivos. Por esse contexto, este artigo analisar a trajetória experiencial de um projeto de logística reversa de componentes eletrônicos no estado de Mato Grosso, por meio da interação entre universidade-empresa. Abordagem da pesquisa é qualitativa de caráter descritivo com método de estudo de caso único. Foi acompanhado em campo o projeto e realizada uma entrevista com professor pesquisador que contribuiu para sua efetividade. Os resultados apontaram uma sinergia estratégica da empresa de engenharia reversa e a sociedade na viabilidade do processo de reciclagem.
\end{abstract}

Palavras-chave: Logística Reversa; Lixo Eletrônico; Responsabilidade Socioambiental.

1 Texto inicial apresentado e publicado em: SOUZA, Djeimella Ferreira de; SILVA, Loanna Rodrigues; NAGAI, Nathália Prochnow; DESIDÉRIO, Paulo Henrique Martins. A logística reversa e a reciclagem de componentes eletrônicos como opçóes sustentáveis: Análise de um projeto no Estado de Mato Grosso. In: CONASUM - CONGRESSO DE ADMINISTRAÇÃO DO SUL DE MATO GROSSO, 3., 2015, Rondonópolis-MT, Anais... Universidade Federal do Mato Grosso, Campus Rondonópolis-MT, 2015.

2 Administradora pela Universidade Federal de Mato Grosso, Doutoranda em Inovação Tecnológica e Biofarmacêutica na Universidade Federal de Minas Gerais, e-mail: djeimellaferreira3@gmail.com

3 Graduadas em Administração - ICHS - CUR - UFMT, e-mail: loanna_phn@hotmail.com

4 Graduadas em Administração - ICHS - CUR - UFMT, e-mail: loanna_phn@hotmail.com

5 Orientador do trabalho. Professor Doutor do Curso de Administração do ICHS - CUR - UFMT, e-mail: phenrik@gmail.com 


\title{
THE REVERSE LOGISTICS AND THE RECYCLING OF ELECTRONIC COMPONENTS AS SUSTAINABLE OPTIONS: ANALYSIS OF A PROJECT IN MATO GROSSO
}

\begin{abstract}
The process of technological innovation in electronic components allowed unrestricted access of society to information and technological products in their daily lives. However, the speed of the schumpterian perspective of creative destruction in the substitutions of these products for better promoted an impact in the policies of environmental management, the one of electronic waste. In this way, a discussion of the reverse paths of these equipments can minimize relevant environmental effects. It's also noticed a search of the industry for materials with less environmental impact, reuse capacity and possibility of reduction of productive costs. This article analyzes the experiential trajectory of reverse logistics project of electronic components in the state of Mato Grosso, through the interaction between university-company. Research approach is qualitative of descriptive character with case study method. The project was followed in the field and an interview was conducted with research professor. The results showed a strategic synergy of the reverse engineering company and the company in the viability of the recycling process.
\end{abstract}

Keywords: Reverse Logistics; Electronic Wast; Environmental Responsibility.

\section{INTRODUÇÁO}

Os efeitos do consumo exacerbado de produtos tecnológicos influenciaram a sociedade serem mais exigentes e preocupados com as questôes ambientais. Este comportamento deriva da preocupaçẫo de um consumidor cada vez mais consciente da limitação dos recursos ambientais. Assim, a sustentabilidade tornou-se amplamente discutida no século XXI, com diversos enfoques sobre o dilema entre as questóes ambientais (reuso e reciclagem) e o custo de produção.

Esta corrente surgiu após a publicação da Comissão Mundial para o Meio Ambiente e Desenvolvimento em 1978, ao definir o conceito de Desenvolvimento Sustentável, diagnosticando a necessidade global de um novo modelo de desenvolvimento. Neste processo de transformação, as organizaçóes passaram a ter um papel fundamental ao desempenhar açōes empresariais voltadas à conscientização ambiental atrelada aos valores a sociedade (SEVEROa et al., 2013).

Segundo Rogers e Tibben-Lembke (2001), a logística reversa tem como objetivo principal reduzir a poluição do meio ambiente e os desperdícios de insumos, assim como a reutilização e reciclagem de produtos. Os autores relatam que o reaproveitamento de materiais e a economia com embalagens retornáveis têm trazido ganhos que estimulam cada vez mais iniciativas e esforços para implantação da logística reversa, visando à eficiente recuperação de produtos.

No setor de eletro-eletrônico, os problemas se tornaram ainda mais emergente, visto que o consumo por novos produtos é alto e contínuo, além disto, o ciclo de vida dos mesmos é curto, produzindo assim um excedente sem reuso denominado por lixo eletrônico. Com isto, levantou-se o seguinte questionamento da pesquisa: Como se desenvolveu um projeto de componentes eletrônicos no Estado de Mato Grosso por meio da interaçáo universidadeempresa 
Desta forma, o presente artigo objetivou analisar a trajetória experiencial de um projeto de logística reversa de componentes eletrônicos no estado de Mato Grosso, por meio da interaçấo entre universidade-empresa. A abordagem da pesquisa é qualitativa e descritiva na opçáo de estudo de caso. $\mathrm{O}$ instrumento da pesquisa foi um questionário semiestruturado com o professor da Universidade Federal de Mato Grosso.

Portanto, o estudo divide-se em cinco partes, sendo a primeira introdutória com uma visão geral sobre a temática discutida, a segunda é construída pela revisão teórica que abordou os aspectos da gestấo ambiental, lixo eletrônico e a logística reversa. A terceira parte descreve os procedimentos metodológicos. $\mathrm{Na}$ quarta são apresentados os resultados obtidos do estudo de caso único. Por fim, são expostas as consideraçôes finais do estudo.

\section{ECOINOVAÇÃO E INTERAÇÃO UNIVERSIDADE-EMPRESA}

Para conceituar o termo ecoinovação é preciso o entendimento o que é a inovação. Conhecido como "pai da inovação", o economista Schumpeter (1961) foi o primeiro a conceituar a inovação, o mesmo considerava que para ocorrer o desenvolvimento econômico seria necessário impulsionar de forma dinâmica as atividades produtivas, isto porque, cada vez que a firma cria novos produtos ou novas modificaçóes de produtos combinados com os recursos e os fatores de produção, outras firmas irão imitar os concorrentes, portanto outras inovações surgirão e a contínua busca por criação gerará novos ciclos de negócio, este processo foi denominado pelo economista de "destruição criadora" (SCHUMPETER, 1961). A partir daí, diversos outros autores foram acrescentando abordagens, porém sempre se referindo a lógica do pensamento de Schumpeter.

Em relação ao termo "eco", propagado pelo meio científico internacional, são inovaçóes voltadas para as questōes da sustentabilidade (WAGNER, 2010; REID e MIEDZINSKI, 2008), alem disto, foram surgindo outros termos para referir sobre sustentabilidade como: inovações ambientais, inovações verdes, inovaçóes ecológicas e assim por diante.

A necessidade de pensar em sustentabilidade iniciou na década de 70 , começaram a surgir publicaçóes científicas pelo Clube de Roma, ganhou notoriedade quando foi apresentado na Conferência das Naçóes Unidas de Estocolmo, em 1972, a respeito dos desequilíbrios causados na terra pelo avanço da industrializaçâo. Em 1987, foi criada uma comissão dentro das Naçóes Unidas para questôes mundiais relacionadas ao Meio ambiente, com intuito de propor cooperaçôes internacionais a cerca do tema gerando assim, o Relatório Bruntland, conhecido como "Nosso Futuro Comum" (COMISSÃO MUNDIAL SOBRE MEIO AMBIENTE E DESENVOLVIMENTO, 1991).

Assim, os estudos sobre as questóes ambientais são recentes e vem sendo difundido nas pesquisas científicas e estudos organizacionais ramificando em várias abordagens: (1) adequação de modelos de negócio (FADHILAH e RAMAYAH, 2012; OECD, 2012; BOONS e LÜDEKE-FREUND, 2013). (2) ecoeficiência na produção sustentável, ciclo de vida e gestão verde da cadeia de suprimentos (GMELIN e SEURING, 2014; OECD, 2009b; SEMAN et al., 2012). (3) a relação entre as inovaçóes ambientais como fontes de vantagem competitiva e incremento da competitividade (PORTER e VAN DER LINDE, 1995; NIDUMOLU et al. 2009; SEVEROb et al., 2015). (4) desenvolvimento de novos 
produtos sustentáveis (BAUMANN et al., 2002; HUANG e WU, 2010; MEDEIROS et al., 2012; GMELIN e SEURING, 2014).

Segundo Baumann et al. (2002) na perspectiva do desenvolvimento de produtos verdes na perspectiva das empresas são necessário distinguir 3 (três) áreas: i) tomada de decisão estratégica e resolução de problemas em negócio e desenvolvimento de produto. ii) Design do produto, e iii) marketing verde.

A abordagem deste estudo esta no desenvolvimento de produtos sustentáveis. Isto porque, os produtos afetam o meio ambiente em muitos pontos da cadeia de extração de matéria prima até a gestão dos resíduos. Estes efeitos ambientais resultam de interrelações a tomada de decisóes em vários estágios do ciclo de vida do produto.

Essa perspectiva é gerada, sobretudo, porque a inovação geralmente tem sua origem com aqueles que criam soluçóes para suas próprias necessidades (SCHILLING, 2013). E, um dos principais fomentadores da inovação são a universidade e a empresa, principalmente com a interação entre ambas, percorrendo assim estágios da inovação até o produto ser lançado ao mercado, conforme estágios demonstrados na Tabela 1.

Tabela 1 - Estágio da inovação: Tempo e o custo

\begin{tabular}{l|c|c}
\hline \multicolumn{1}{c|}{ Estágio } & Tempo & Custo* \\
\hline 0 - Tenho uma ideia! & & \\
\hline 1- Formular e descrever o esboço & 1 Semana & $\$ 100$ \\
\hline 3- Desenhar e definir especificaçóes & 2 Semanas & $\$ 1.000$ \\
\hline 4 A- Desenvolver o protótipo e testar & 1 Mês & $\$ 10.000$ \\
\hline 4 B- Estratégia de mercado & & \\
\hline 4 C- Avaliaçáo do planejamento estratégico e análise de risco VPL. & 2 Meses & $\$ 100.000$ \\
\hline 5 A- Escala, construir planta piloto & & \\
\hline 5 B- Teste de mercado & 8 Meses & $\$ 1$ Milhão \\
\hline 6 A- Construir a planta & 16 Meses & $\$ 10$ Milhóes \\
\hline 6 B- Promover, lançar, mercado & & \\
\hline
\end{tabular}

Fonte: Schilling (2013)

*Custo em dólar.

No Brasil, de acordo com a Pesquisa de Inovação (PINTEC) entre 2003 e 2005, a capacidade inovadora das indústrias brasileiras foi bastante elevada $20 \%$ das empresas tinham desenvolvido um novo produto, $27 \%$ desenvolvido um novo processo e $13 \%$ desenvolvido os dois tipos de inovação (IBGE, 2005). Sendo que, mais de um terço (38\%) das empresas que colaboraram para inovação, o seu parceiro mais próximo foi uma universidade.

Embora o Brasil seja uma nação incipiente em termos de ciência nas entradas e saídas de tecnologia, existem grandes empresas multinacionais alocadas no país, impactando na qualidade nas interaçóes das universidades e empresas como intuito de aumentar o investimento em pesquisa e desenvolvimento (ARRUDA et al. 2006). 
Os benefícios da interação universidade-empresa são: o desenvolvimento de protótipos e de novas técnicas e instrumentos, sugestão de novas ideias, assistência na complementação de projetos existentes, fornecimento de materiais para o desenvolvimento de produtos durante o período inicial da firma na tecnologia, acesso ao conhecimento tecnológico (COHEN et al. 2002; FALKNER e SENKER, 1994).

Com isso, Hamel e Prahalad (1995) ponderam como uma oportunidade de diferenciação competitiva em longo prazo pelos empresários. Deste modo, além de gerar novas oportunidades de negócios, a questão ambiental pode propiciar o surgimento de inovações tecnológicas significativas.

Portanto, os requisitos ambientais devem ser levados no processo de design minimizando desde as matérias primas, consumo de energia, geração de resíduos, risco de saúde, segurança e degradação ecológica, consumidor, fornecedor. Entretanto, apesar de diversas empresas adotarem medidas sustentáveis não soluciona a gestão do resíduo dos produtos. Por isso, o novo tópico apresenta sobre a temática da logística reversa.

\section{LOGÍSTICA REVERSA DO LIXO ELETRÔNICO}

A logística reversa é um dos instrumentos introduzido pela Política de Resíduos Sólidos através da Lei $\mathrm{n}^{\mathrm{o}} 12.305$, com intuito de compartilhar a responsabilidade pelo ciclo de vida dos produtos com os stakeholders.

Ferreira (2009) afirma que não existe uma definição 'universal' para o termo, logística reversa, costuma-se utilizar o conceito apresentado pelo Reverse Logistics Executive Council como o "processo do planejamento, implementação e controle da eficiência e custo do fluxo de matérias-primas, estoques em processo, produtos acabados e as informaçóes correlacionadas do ponto do consumo ao ponto de origem com o propósito de recapturar valor ou para uma disposição apropriada”.

Ballou (2006, p. 27) aborda a logística reversa com foco na eficiência e eficácia dos processos de planejamento, implantação e controle do fluxo de mercadorias, serviços e das informações relativas do ciclo de produção até ao cliente.

Ao implementar a logística reversa nas organizaçóes abrange o âmbito econômico com a diminuiçáo dos custos de produçáo e surgimento de novos negócios a longo prazo, e o social com a sobrevivência das espécies, minimizando assim impactos no meio ambiente (SOUSA, 2011).

São denominados Resíduos de Equipamentos Eletro Eletrônicos (REEE) computadores, impressoras, rádios, televisores, geladeiras e telefones celulares, são uma mistura complexa de materiais e componentes (EUROPEAN COMISSION, 2015).

Segundo STEP (2014)- uma aliança entre ONU, empresas, governos e ONGs do mundo- lançaram um mapa global do e-lixo, por sua vez, um gargalo que os países mundiais buscam mitigar, no Brasil, em 2012 produziu mais de 1 milhão tonelada de lixo eletrônico. Assim, não é trivial ao implementar a logística reversa do e-lixo, por isso, é relevante ressaltar as contribuiçôes de Rahman e Subramanian (2011) que influenciam a tomada de decisão no Quadro 1. 
Quadro 1: Fatores de Implementação da Logística Reversa do e-lixo

\begin{tabular}{|c|c|c|}
\hline Fator & Ampla conclusáo & Fonte \\
\hline Legislação & $\begin{array}{l}\text { Legislação é um dos motores bem } \\
\text { sucedido para a cadeia de suprimento } \\
\text { reverso e também age como um } \\
\text { motivador para boas praticas sustentáveis } \\
\text { de inovaçáo de baixo custo. }\end{array}$ & $\begin{array}{l}\text { Carter e Ellran (1998), Bowen et } \\
\text { al (2001), Knemeyer et al. (2002), } \\
\text { Dowlatshahi (2005), Walker et al. } \\
\text { (2008), ;Tan e Kumar (2006) }\end{array}$ \\
\hline $\begin{array}{c}\text { Demanda de } \\
\text { Cliente }\end{array}$ & $\begin{array}{l}\text { A demanda de cliente faz com que as } \\
\text { empresas, sejam socialmente responsáveis } \\
\text { a incluir práticas de gestáo ambiental em } \\
\text { suas cadeias de suprimentos }\end{array}$ & \begin{tabular}{l}
\multicolumn{4}{l}{ Lamming e Hampson (1996), Carter } \\
e Ellram (1998), Bowen (2000), \\
Hall (2001), Carter e Dresner \\
$(2001)$, Álvarez-Gil et al (2007), \\
Kapetanopoulou e Tagaras (2010).
\end{tabular} \\
\hline $\begin{array}{l}\text { Estratégia } \\
\text { Custo/ } \\
\text { Benefício }\end{array}$ & $\begin{array}{l}\text { A estratégia de custos na implementação } \\
\text { da logística reversa trará benefícios } \\
\text { diretos e indiretos substanciais para a } \\
\text { empresa. }\end{array}$ & $\begin{array}{l}\text { Andel and aichlmayr (2002) Mason, } \\
\text { (2002), Teunter e Van der Laan } \\
\text { (2002), Dowlastshahi (2005), Ravi et } \\
\text { al. (2005), Guide et al. (2006), Guide } \\
\text { e Van Wassenhove (2009). }\end{array}$ \\
\hline $\begin{array}{l}\text { Volume e } \\
\text { Qualidade }\end{array}$ & $\begin{array}{l}\text { Qualidade do produto devolvido } \\
\text { aproveita os custos do transporte da } \\
\text { cadeia de suprimento reversa. Preços } \\
\text { com base na qualidade amplifica o } \\
\text { volume de devoluçóes. }\end{array}$ & $\begin{array}{l}\text { Carter e Ellram (1998), Knemeyer et } \\
\text { al. (2002), Tibben-Lembke e Rogers } \\
\text { (2002), Murphy e Poist (2003), } \\
\text { Dowlatshahi (2005), Ravi et al. } \\
\text { (2005), Pokharel e Mutha (2009). }\end{array}$ \\
\hline Incentivo & $\begin{array}{l}\text { O Alinhamento adequado de } \\
\text { incentivos entre parceiros nas cadeias } \\
\text { de suprimentos reversa ira melhorar as } \\
\text { taxas de retorno e o comportamento. }\end{array}$ & $\begin{array}{l}\text { Carter e Ellram (1998), Savaskan et } \\
\text { al (2004), Ferguson e Toktay (2006), } \\
\text { Pokharel e Mutha (2009). }\end{array}$ \\
\hline Recurso & $\begin{array}{l}\text { Alocação adequada e utilização eficaz } \\
\text { dos recursos disponíveis para as } \\
\text { operaçóes da cadeia de suprimento } \\
\text { reversa, juntamente com a estratégia de } \\
\text { produto apropriado renderia ativos para } \\
\text { a empresa. }\end{array}$ & $\begin{array}{l}\text { Stock (1998), Dolatshahi (2005), } \\
\text { Daughrty et al (2005), Richey et al. } \\
\text { (2005), Pokharel and Mutha (2009), } \\
\text { Kapetanopulou e Tagaras (2010). }\end{array}$ \\
\hline $\begin{array}{l}\text { Integração e } \\
\text { Coordenação }\end{array}$ & $\begin{array}{l}\text { Coordenação da cadeia de abastecimento } \\
\text { reversa e integraçáo do sistema de } \\
\text { suporte de informaçáo aumentariam } \\
\text { a velocidade da recuperação e } \\
\text { rentabilidade da empresa. }\end{array}$ & $\begin{array}{l}\text { Hess e Meyhew (1997), Carter e } \\
\text { Ellram (1998), De Brito et al (2002), } \\
\text { Fleishchamnn (2003), Daugherty } \\
\text { et al (2005), Yalabik et al (2005), } \\
\text { Chouinard et al (2005), Tan e Kumar } \\
\text { (2006), Guide e Van Wassenhove } \\
(2009)\end{array}$ \\
\hline
\end{tabular}

Fonte: adaptado de Rahman e Subramanian (2011). 
No Brasil, a reciclagem do e-lixo é direcionada, principalmente, para usinas de reciclagem, onde eletrodomésticos, computadores, telefones celulares e todos os tipos de dispositivos não utilizáveis são reduzidas para materiais básicos da indústria, como plástico e metais, em seguida, fornecidos aos níveis primários de produçóes industriais.

Além da alta produção de e-lixo, o país trata de forma distinta a gestão de resíduos, na qual os fabricantes e distribuidores operam a logística reversa em seus próprios produtos, optam por vender os que consideram secundários. Essas empresas que compram esses produtos fazem a logística reversa, desmantelam os produtos e materiais, nisso os caminhos pra o produto eletrônico descartado são variados e acabam em várias etapas do processo de produção o que torna o tamanho do mercado difícil de avaliar (NES, 2014).

Apesar dos benefícios da recuperação da reciclagem de resíduos do lixo eletrônico até mesmo em países desenvolvidos como EUA é limitada devido a: coleta insuficiente; nenhuma legislação ou política federal obrigando a gestão de resíduos; falta de tecnologias de reciclagem e valorização; e a exportação ilegal de resíduos de lixos perigosos para países em desenvolvimento (ZENG et al., 2013).

Em síntese, as limitações nos benefícios para incentivos de projetos em logística reversa no âmbito de reciclagem de lixos eletrônicos não descaracteriza o envolvimento dos atores governo-universidade-empresa, conceitualmente conhecido no modelo Hélice Tríplice apresentado por Etzkowitz e Leydesdorff (2000). O envolvimento destes elos no projeto potencializa sua viabilidade econômica de operação e escalabilidade no mercado.

\section{PROCEDIMENTOS METODOLÓGICOS}

Este artigo objetivou analisar a trajetória experiencial de um projeto de logística reversa de componentes eletrônicos no estado de Mato Grosso, por meio da interação entre universidade-empresa.

Os integrantes do projeto foram: Universidade Federal de Mato Grosso (UFMT), a empresa Recyclart atua na área de reciclagem tecnológico utilizando a tecnologia de fim de vida útil (FVU) que valoriza as matérias primas contidas nos resíduos de equipamentos elétricos e eletrônicos (REEE) e o SENAI-MT na criação de uma tecnologia patenteada capaz de capturar metais preciosos, como o ouro, em placas de equipamentos eletrônicos.

A abordagem da pesquisa é qualitativa com caráter exploratório, com o método de estudo de caso único (YIN, 2015), sob qual a coleta de dados foi por meio de entrevista semi-estruturada com o professor pesquisador no laboratório Knowledge Management, no departamento de Administração da UFMT. A entrevista com o pesquisador ocorreu em 2016 no laboratório do mesmo.

O pesquisador entrevistado é graduado em Processamento de dados pela Universidade Federal do Ceará (1982), mestrado em Engenharia de Sistema e Computação pela Universidade Federal do Rio de Janeiro (1991) e doutor em Engenharia de produção pela Universidade Federal do Rio de Janeiro (1999). Atualmente é professor adjunto da Universidade Federal de Mato Grosso, ocupa o cargo de Diretor da Faculdade de Administração na universidade. Possui experiência nas áreas: gestão do conhecimento, 
ciência da computação, engenharia da informação, administração da produção, tecnologia e sociedade (CNPq, 2018).

Nesse sentido, o estudo seguiu um roteiro de entrevista previamente estabelecido para coleta das percepçóes do pesquisado em relação ao projeto. Conforme a Figura 1, o desenho da pesquisa com as etapas da realização.

Figura 1: Desenho da pesquisa

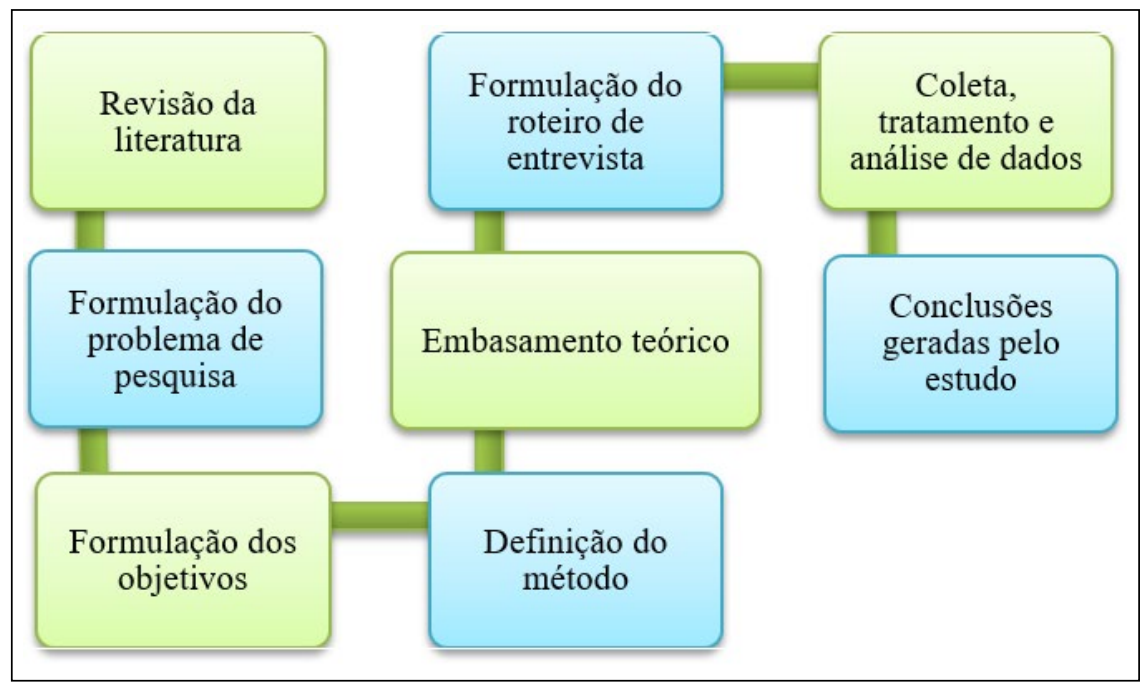

Fonte: Elaborado pelos autores.

Após realização da entrevista com o pesquisador responsável pela implantação e interface do projeto com os demais atores participantes, foi efetuada análise do conteúdo para identificação dos elementos centrais do projeto do equipamento de reciclagem. Também foram identificados os materiais divulgados do protótipo de reciclagem para análise dos resultados.

\section{ANÁLISE E DISCUSSÃO DOS RESULTADOS}

Em 2006, deu-se iniciou ao projeto de interação. Estruturalmente os responsáveis pelo projeto foram delimitados em função primordial: (1) Recyclart: empresa idealizadora do produto. (2) Pesquisador: responsável pela Pesquisa e Desenvolvimento (P\&D) do produto. (3) SENAI: Financiadora e executora do projeto.

Para ocorrer uma inovação existem diversos níveis que vai desde a ideia até o lançamento do produto ao mercado. Em 2006, nasceu a ideia de construir uma máquina capaz de capturar os metais preciosos de placas de produtos eletrônicos pelo empreendedor Carlos Israilev, dono Recyclart. Com o financiamento e parceria com a UFMT foram 6 (seis) anos de pesquisa até criar o protótipo da máquina, denominado de ERPCI-150 (Equipamento para reciclagem de placas de circuito impresso), segundo o professor o protótipo coloca o Brasil entre os seis países detentores deste tipo de tecnologia "hard science". 
Segundo o pesquisador, o processo de logística reversa que o protótipo ERCPI 150 funciona da seguinte forma: Primeiro, é colocado as placas de circuito de impressão (PCI) e componentes eletrônicos contidos nos produtos eletrônicos, através da aplicaçáo de uma suíte automatizada. Segunda etapa é a trituração, em que passa por 3 (três) fases: a eletromagnética, gravimétrica e magnética. Após a trituração, inicia a terceira fase, a separação do material reciclado em três segmentos: ferroso, não ferroso e não metálico. A capacidade média de produção do protótipo é processar até $150 \mathrm{~kg}$ de placas de circuito impressão por hora. Essa quantidade de produtos reciclados.

Cada matéria-prima reciclada é direcionada para uma cadeia produtiva, conforme a Figura2.

Figura 2: Processo de Logística reversa do protótipo ERCPI-150

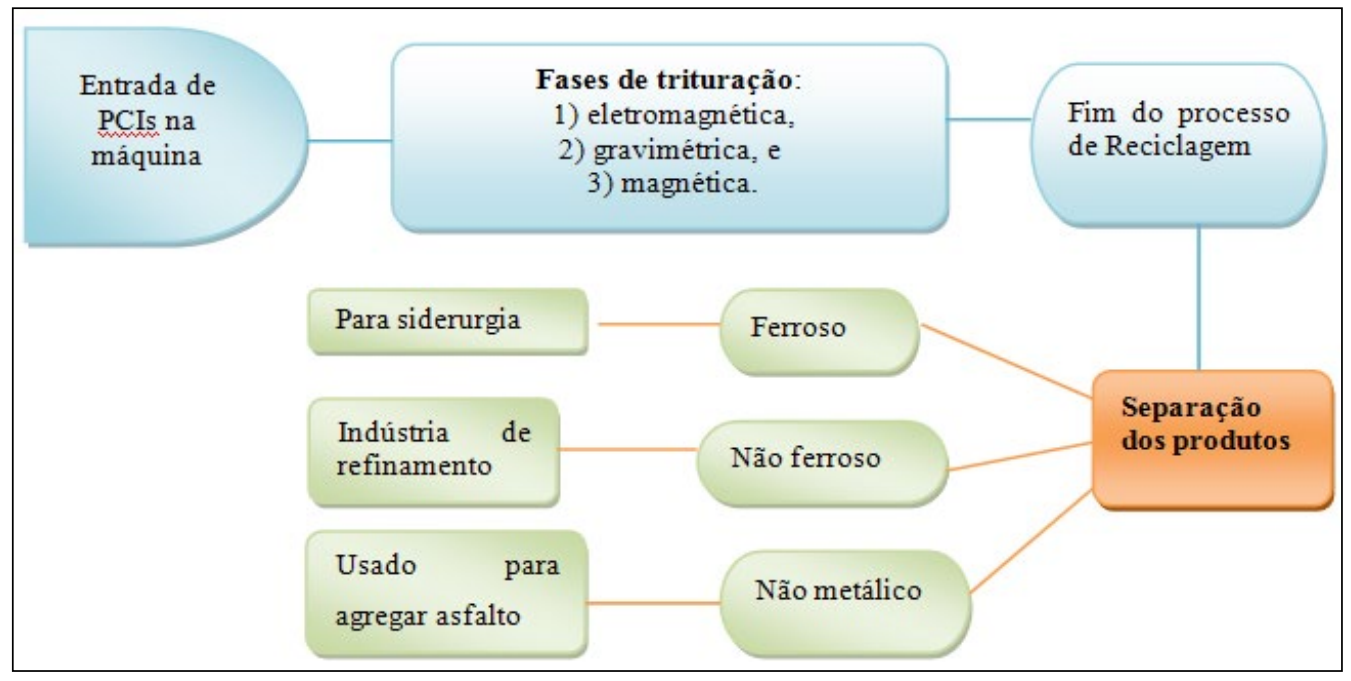

Fonte: Elaborado pelos autores

O papel do professor pesquisador no projeto foi à modelagem do Protótipo, denominado pelo mesmo de "artefato", e os mecanismos de medição de qualidade das matérias primas recicladas pela máquina. Além disto, as reuniôes entre os integrantes são feitas no laboratório do professor.

Apesar da criação da máquina finalizada, de acordo com o pesquisador o projeto passou por novos desafios, sendo eles:

(1) O composto reciclado "não ferroso", as indústrias de refinamento não absorvem ainda.

(2) Após a separação a reciclagem, a separação dos produtos ainda é feito em laboratório.

(3) Dificuldade em contratar mão de obra especializada para o desenvolvimento dos componentes (mecânicos, elétricos e eletrônicos) do ERPCI-150. 
(4) Falta de legislação referente ao processo de produção e comercialização dos produtos reciclados que viriam a ser lixos eletrônicos.

O projeto encerrou ao concluir o protótipo, as etapas de teste e o estudo de mercado. Durou 3 (três) anos para construir o ERPCI e custou R \$ 640 mil. Atualmente o empreendedor esta desenvolvendo pesquisa para otimizar o processo da máquina, e incluir 8 modelos de trituraçôes, mais veloz e com capacidade de fazer leitura dos componentes sem modificar a configuração do sistema, por meio da parceria entre a Universidade Federal de Mato Grosso (professor pesquisador Einstein Aguiar), e a Escola de Engenharia de São Carlos - SP (professor pesquisador Denis Brandão). Prospecta-se investimentos para implementar o processo de produçáo com larga escala. De acordo com a análise do mercado a máquina é viável para atender a indústria de pequeno.

Portanto, com a experiência da interação entre universidade-empresa permitiu observar que gerar inovação não é trivial e quando parte para questóes ambientais enfrenta outros gargalos, um deles em principal é a legislação, no Brasil a Lei 1991/07 que regula o descarte no Brasil náo define os parâmetros de como deve ser feito. Sendo assim, os caminhos para produtos eletrônicos descartados no país são variados e acabam em várias etapas do processo de produção, o que torna o tamanho total do mercado difícil de avaliar, assim como o elevado número de empresas não regulamentadas que operam em escala local (NES, 2014).

Portanto, mesmo ao desenvolver tecnologia inovadora que contribui para o meio ambiente ao realizar a reciclagem de eletroeletrônica, necessita de lei para amparar o desenvolvimento da máquina e assim atingir o último nível de inovação que inclui a fase de comercialização.

\section{CONSIDERAÇÓES FINAIS}

A logística reversa mostra-se como grande oportunidade de desenvolver a sistematização dos fluxos de produtos ou resíduos descartados, seja pelo motivo de vida útil, seja por obsolescência tecnológica com o seu reaproveitamento, dentro ou fora da cadeia produtiva de origem. Assim, pode-se contribuir para redução do uso de recursos naturais e dos demais impactos ambientais o desenvolvimento de projetos que incluam materiais recicláveis em determinada cadeia produtiva.

Este trabalho mostrou a importância da logística reversa e seu potencial papel estratégico dentro de uma empresa, agregando vantagem competitiva e contribuições à redução de custos. Essa temática tende a ampliar sua discussão na atualidade, ocasionada pela reformulaçáo do comportamento do mercado e demandas por empresas que olham com maior cautela o meio ambiente e a destinação de seus resíduos.

É de suma importância para a sociedade o conhecimento de projetos que visam à correta destinação do lixo para reutilização ou outras destinaçôes. O protótipo desenvolvido em Mato Grosso é mais um passo para o caminho trilhado por diversas empresas que tem esse olhar de que é possível ter retorno com modelos de negócios ligados à reciclagem de materiais eletrônicos. 
A implantaçấo da logística reversa nas empresas colabora para a tomada de consciência de seus gestores, quanto à existência do problema de devoluçóes de insumos e lixos eletrônicos e seus impactos no meio ambiente. Há contribuição quanto à implantação de açôes corretivas a partir das necessidades e expectativas dos clientes, na inovação de processos internos e vantagem competitiva em relação aos concorrentes.

A logística reversa, em conjunto com a reciclagem, forma um passo fundamental para o futuro com disponibilidade de recursos finitos e reflexão do uso consciente e adoção tecnológica em reuso de insumos na área produtiva.

Permite também que as indústrias sejam alimentadas por materiais reciclados, gerando um círculo virtuoso, onde milhares de toneladas de lixos eletrônicos deixam de ser depositados nos lixóes, diminuindo assim os passivos ambientais das indústrias, ao mesmo tempo em que diminui consideravelmente a extraçáo dessa matéria-prima na natureza.

As limitaçóes da pesquisa se ancoram no melhor detalhamento dos processos envolvidos no projeto de reciclagem, como também na realização de entrevistas com os demais atores envolvidos nas etapas de construçáo do equipamento e de sua operaçáo.

Sugere-se como estudo futuro a viabilidade econômica das empresas que atuam com reciclagem de lixo eletrônico no mercado e sua sedimentação em demais regiōes no país para melhor distribuir as açōes de logística reversa.

\section{REFERENCIAS}

ARRUDA, M.; VERMULM, R.; HOLLANDA, S. Inovaçáo Tecnológica no Brasil. São Paulo: ANPEI, 2006.

BALLOU, R. H. Gerenciamento da cadeia de suprimentos/logística empresarial. 5. ed. São Paulo: Bookman, 2006.

BAUMANN, H.; BOONS, F.; BRAGD, A. Mapping the Green Product Development Field: Engineering, Policy and Business Perspectives. Journal of Cleaner Production, Gotemburgo, v. 10, n. 5, p. 409-425, 2002.

BOONS, F., LEUDEKE-FREUND, F. Business models for sustainable innovation: state of the art and steps towards a research agenda. Journal of Cleaner Production 45, 9-19. 2013.

Cohen, W. M.; Nelson, R. R.; Walsh, J. P. The influence of public research on industrial R\&D. Management Science, v. 48, n. 1, p. 1-23, January 2002.

COMISSÃO EUROPEIA. Resíduos de Equipamentos Eletro Eletrônicos. Disponível em>: http://ec.europa.eu/environment/waste/weee/index_en.htm<. Acesso 07 jun 2018.

COMISSÃO MUNDIAL SOBRE O MEIO AMBIENTE E DESENVOLVIMENTO. Nosso Futuro Comum. 2 ed. Rio de Janeiro: Editora da Fundação Getúlio Vargas, 430 p., 1991. 
CNPq. Curriculum lattes. Disponível em:> http://buscatextual.cnpq.br/buscatextual/ visualizacv.do?id=K4799484E6< Acesso 13 jun 2018.

ETZKOWITZ, H.; LEYDESDORFF, L. The dynamics of innovation: from national systems and "Mode 2" to a triple helix of university-industry-government relations.

FAULKNER, W.; SENKER, J. Making sense of diversity: public-private sector research linkages in three technologies. Research Policy, v. 23, n. 6, p. 673-695, November 1994.

FERREIRA, J. M. B.; FERREIRA, A. C. A sociedade da informação e o desafio da sucata eletrônica. Revista de Ciências Exatas e Tecnologia, vol. 3, n. 3, 2008.

FADHILAH, Z.; RAMAYAH, T. Behind the Green Doors: what management Practices Lead to Sustainable Innovation? Procedia Social and Behavioral Sciences, v. 65, p. $247-$ 252, dez. 2012.

GMELIN, H.; SEURING, S. Determinants of a sustainable new product development. Journal of Cleaner Production, 69(1), 1-9. 2014.

HAMEL, G.; PRAHALAD, C. K. 'Competindo pelo Futuro: estratégias inovadoras para obter o controle do seu setor e criar os mercados de amanhá. Rio de Janeiro: Campus: 1995.

HUANG, Y. C.; WU, Y. C. J. The Effects of organizational factors on Green New Product Success: evidence from high-tech industries in Taiwan. Managing Decision, v. 48, n. 10, p. 1539-1567, 2010.

\section{INSTITUTO BRASILEIRO GEOGRAFIA ESTATÍSTICA. Pesquisa de Inovação}

Tecnológica. 2003. Disponível em<http://www.pintec.ibge.gov.br/>. Acesso em 10 mar. 2015.

MEDEIROS, J. F.; RIBEIRO, J. L. D.; CRUZ, C. M. L. Inovação ambientalmente sustentável e fatores de sucesso na percepção de gestores da indústria de transformação. Cadernos EBAPE.BR, v. 10, n. 3, p. 652-676, 2012.

NES, E. F. E-Waste Management in Brazil. 2014. Disponível em >http://techinbrazil. com/e-waste-management-in-brazil>. Acesso em 5 jun 2018.

NIDUMOLU, R.; PRAHALAD, C. K.; RANGASWAMI, M. R. Why sustainability is now the key driver of innovation. Harvard Business Review, set. 2009.

OECD. The Future of Eco-Innovations: the role of business models in green Transformation. Paris: OECD, 2012.

OECD. Sustainable manufacturing and eco-innovation: towards a green economy. Policy Brief, 2009. 
PORTER, M.; VAN DER LINDE, C. Green and competitive: ending the stalemate. Harvard Business Review, set./out. 1995.

RAHMAN, S.; SUBRAMANIAN, N. Factors for implementing end-of-life computer recycling operations in reverse supply chains. Internation Journal Production

Economics 140, 239-248, 2011.

REID, A.; MIEDZINSKI, M. Eco-innovation - final report for Sectoral Innovation Watch. Final report to Europe INNOVA iniative. Technopolis Group, 2008. Disponível em: . Acesso em: 7 jun. 2018.

ROGERS, D. S.; TIBBEN-LEMBKE, R. An examination of reverse logistics practices. Journal of Business Logistics, v. 22, n. 2, p. 129-148, 2001.

SCHUMPETER, J. A. Capitalismo, socialismo e democracia. Rio de Janeiro: Fundo de Cultura, 1961.

SCHILLING, M. A. Strategic Management of Technological Innovation. 4th edition. McGraw-Hill, 2013.

SEMAN, N. A. A.; ZAKUAN, N.; JUSOH, A.; ARIF, M. S. M.; SAMAN, M. Z. M. The relationship of green supply chain management and green innovation concept. ProcediaSocial and Behavioral Sciences, n. 57, p. 453-457, 2012.

SEVEROa, E. A. ; GUIMARÁES, J. C. F. ; DORION, E. ; NODARI, C. H. Produção mais limpa com ênfase na sustentabilidade ambiental e performance organizacional: um estudo empírico no sul do brasil. In: 4th International Workshop Advances in Cleaner Production, São Paulo, 2013.

SEVEROb, E. A.; GUIMARÁES, J. C. F; DORION, E. C. H; NODARI, C. H. Cleaner production, environmental sustainability and organizational performance: an empirical study in the Brazilian Metal-Mechanic industry. Journal of Cleaner Production, v. 96, p. $118-125,2015$.

SOUSA, S. F; FONSECA, S. U. L. Logística Reversa: Oportunidades para Redução de Custos em Decorrência da Evolução do Fator Ecológico. Revista Terceiro Setor, v. 3, n. 1, p. 29-39, 2009.

STEP, Initiative. Solving The E-Waste Problem. Overview of e-waste related information - Brazil.2014. Disponível em: . Acesso em: 19 jan. 2018.

ZENG, X. L.; LI, J.H; STEVELS, A. L. N; LIU, L. L. Perspective of electronic waste management in China based on a legislation comparison between China and the EU. Journal of Cleaner Production, v. 51, p. 80-87, 2013. 
ZOETEMAN, H. R.; KRIKKE, H. R.; VENSELAAR, J. Handling WEEE waste flows: on the effectiveness of producer responsibility in a globalizing world. International Journal Advanced Manufacturing Technology, v. 47, p. 415-436, 2010.

WAGNER, M. The role of corporate sustainability performance for economic performance: a fi rm-level analysis of moderation effects. Ecological Economics. v. 69, n. 7, p. 1553-1560, maio 2010.

YIN, R. K. Estudo de caso: planejamento e métodos. Porto Alegre: Bookman, 2015. 